\title{
A Study on Quantitative Evaluation of Calligraphy Characters
}

\author{
Zelong $\mathrm{Wang}^{1}$, Mengyuan Liao ${ }^{1}$ and Zenichiro Maekawa ${ }^{2}$ \\ 1. Department of Advanced Fibro-Science, Kyoto Institute of Technology, Kyoto 606-8585, Japan \\ 2. Future-Applied Conventional Technology Center, Kyoto Institute of Technology, Kyoto 606-8585, Japan
}

\begin{abstract}
In this study, a numerical method was proposed to evaluate the calligraphy work called calligraphy evaluation system. Four classical chirographies of "Kaisho", "Gyosho", "Sousho" and "Hiragana", and 47 characters for each chirography, were selected and analyzed by this system. The "Sumi" distribution of character was clarified from 12 directions and summarized into four parts of horizontal part, diagonal left part, vertical part and diagonal right part. The character's contour line was converted to a signal data in order to calculate roundness index. The degree of character's radian was presented by roundness index. The smooth index was calculated at the same time. Additionally, width index, "Sumi" ratio, stability index also were calculated to contrast the features of each style. The main character points of four styles of "Kaisho", "Gyosho", "Sousho", "Hiragana" were extracted to compare each other, and provide a reference for learners. The learners could obtain the quantitative data to understand their work's characteristics. It can also be compared with other person's work by this system in order to improve learners' writing skill.
\end{abstract}

Key words: Calligraphy, chirography, quantization, evaluation, regular script, running script, cursive script, hiragana.

\section{Nomenclature}

$\begin{array}{ll}\text { "Kanji": } & \begin{array}{l}\text { Chinese character. } \\ \text { "Kaisho": }\end{array} \\ \text { Regular script, a kind of chirography of } \\ \text { Chinese character. } \\ \text { "Gyosho": } & \begin{array}{l}\text { Running script, a kind of chirography of } \\ \text { Chinese character. }\end{array} \\ \text { "Sousho": } & \begin{array}{l}\text { Cursive script, a kind of chirography of } \\ \text { Chinese character. }\end{array} \\ \text { "Hiragana": } & \begin{array}{l}\text { Japanese character. } \\ \text { Xuan paper is a kind of paper originating in } \\ \text { ancient China used for writing and painting, } \\ \text { which is used for conveying the artistic } \\ \text { expression of both Chinese calligraphy and }\end{array} \\ \text { "Xuant paper. } & \text { The ink of calligraphy. }\end{array}$

\section{Introduction}

The purpose for the creation and development of character writing was to preserve human communication and create a way to characterize the racial culture, which was the result of the joint efforts of all mankind through ages of social practice. There are a variety of characters exist in the world, which

Corresponding author: Zenichiro Maekawa, Dr. Eng., senior fellow of Kyoto Institute of Technology, Applied traditional engineering. are divided into two big flows of the phonogram and the ideograph at present.

The history of Chinese writing extends back more than 6,000 years, and "Kanji" is the root of China and has the history of 4,000 years [1]. The "Kanji" is one of most important representatives of the ideographs, which are the oldest written words of any language in the world. It is well known that "Kanji" is a representative of the ideographs and the alphabet is a representative of the phonograms, which is the main carrier of calligraphic art. The calligraphy, a visual art related to writing, is a splendid star and an exquisite work in Chinese traditional culture, which was also a kind of traditional art popular in Asia, including China, Japan, Korea and Vietnam [2]. Put simply, calligraphy is a kind of creation using brush dips in ink to write characters on "Xuan" paper [3]. Using calligraphy method written beautiful poems on the paper with red seal is a most important and art elegant in Asia. The Japanese character was originated from China, adopted and used Chinese characters. The calligraphy is also a widely practiced and revered art in Japan, 
which is believed to cultivate the heart and improve spirit [4].

Since the invention of "Oracle", a writing is incisions on bones and tortoise shell, Chinese calligraphy font experienced five main stages of development by the seal character, official script, "Sousho", "Kaisho", "Gyosho". The mention of the styles of calligraphy had brought the "Wang Xizhi" [5]. "Wang Xizhi" was the most famous calligrapher traditionally referred to as the Sage of Calligraphy in China, who lived during the Jin Dynasty. He has arguably been one of the most esteemed Chinese calligrapher until, and a master of all forms of Chinese calligraphy, especially the "Gyosho". The one of the most influential "Gyosho" works of "Wang Xizhi" is the "Preface to the Poems Composed at the Orchid Pavilion” (兰亭集序), the preface of a collection of poems by a number of poets when gathering at “Lanting” (兰亭). Wang Xizhi was also reached the peak of perfection for "Kaisho", which brushwork is particularly fine with elegant and unconstrained style while making you feel natural and free. His "Sousho" looks like the wind had blown over the grass in a manner with disorderly and orderly. He not only is appreciated in China, but also has been remained influential in Japanese calligraphy.

Date back to C.E. 804, Japan sent the seventeenth Tang Dynasty missions, whose embassador was "Kadonomaro Fujiwara", assisted embassador was "Ishikawa Michi-eki", accompanied with members including "Kukai", "Saicho" and "TachibananoHayanari", who established the development of Japanese calligraphy immortal feats. Additionally, "Kukai", "Emperor Saga", "TachibananoHayanari" were the famous "three pens" of Japanese calligraphy during the early Heian period [6]. "Kukai" came to "Tang" dynasty and studied as the "Tang" Monks, his calligraphy not only has "Wang Xizhi" style, but also incorporated with "Yan Zhenqing" style, who is a leading Chinese calligrapher and a loyal governor of the "Tang" Dynasty, which influence the Japanese calligraphy for a long period of time.

Japan is one of nations using the ideograph of "Kanji" and the phonogram of "Hiragana" at the same time. Japanese improved and simplified the "Kanji" and then formed the "Hiragana" character, whose forms had changed drastically and made impact on the "Kanji" radicals. Japanese "Hiragana", which originated from China, has evolved to be Japanese unique character over a long time development, which has thin, long and smooth form. There was a long history of using calligraphy to express "Kanji" and "Hiragana" character with the writing brush.

There was a widely accepted calligraphy practice process during the calligraphy training in China according to the writing speed and the coherent between each component of "Kanji": "Kaisho", "Gyosho" and "Sousho". There was also a similar calligraphy practice process in Japan from "Kanji" to "Hiragana". Therefore, "Kaisho" is the foundation of calligraphy, beginner uses "Kaisho" to practice calligraphy. Skilled "Kaisho" was basic condition for written practice Gyosho and Sousho. "Gyosho" is a cross style between "Kaisho" and "Sousho", coherent than "Kaisho", not beyond recognition like "Sousho". Beginners try to raise the writing speed to practice "Gyosho" when they think they can grasp skilled "Kaisho". The "Sousho" and "Hiragana" are the most radical forms of simplifying characters. Learners practice "Sousho" and "Hiragana" after mastering the writing skills of "Kaisho" and "Gyosho". "Sousho" and "Hiragana" were considered as the inspiration for the best carrier, which were often used to be as a platform of playing a creative inspiration by grandmaster.

However, it is very difficult for a learner to see the relationship between the different steps in the progression from basic to advanced during calligraphy learning process. Because the diversity of forms and structures, combined with the complexity of the personal style and involved evaluator's feeling, makes 
the learners very difficult to identify and imitate between different chirography styles, even if copying others work. The evaluation of calligraphy art is a quite subjective work, anyone who wishes to develop writing skill needs to study the technique of writing skill and learn to appreciate chirography art styles. In other words, the creation and evaluation of calligraphy, not only should master of writing knowledge, get rich practical experience, but also need to artistic appreciation ability, such as a good eye, intelligence and intuition, combined with long experience.

The problem of overemphasis of blind training was also existing in calligraphy training, teacher trying to let student improve writing skill by increasing the intensity of training. Usually, learners were taught from teacher by coping practice and oral explanation to study calligraphy skill. However, it is very difficult for the learners to catch the key technical point only based on teachers' demonstration. Scientific understanding for teacher is urgent and useful in the real teaching application. Calligraphy evaluation was a subjective work, and was very hard to quantify, because it was influenced by the chirography and personal style.

In recent years, the study of the quantification of the calligraphy evaluation was advanced with development of the sensitivity evaluation of graphology. The calligraphy fonts automatically generated by computer were studied and developed [7-9]. The numerical way of enhancing the quality of brush style also was focused and studied, which was obtained an image with brush characteristics by computer [10]. With development of the sensitivity engineering including the handwriting study by the sensitivity evaluation, the study for the quantification is advancing [11-13]. However, there was not found a good way to quantitative analysis of the calligraphy writing, which can be widely used to evaluate the several chirographies of calligraphy works written by people with different experience, which was one of start points of this research. The purpose of this study was to establish a quantitative analysis system to evaluate calligraphy work and provided an appreciate software to learner as a reference.

Previous research, we did some preliminary research about the digital evaluation of calligraphy works $[14,15]$. And the characteristics of calligraphy characters between expert and beginner were compared by numerical method [16]. In this study, a calligraphy evaluation system was proposed, which was consisted of the "Direction section analysis system" and "Font shape recognition system" based on the traditional calligraphy evaluation method. Four classical chirographies were paid attention, "Kaisho", "Gyosho", "Sousho" and "Hiragana". In order to provide a valuable reference for the learners, 47 characters related from each chirography were analyzed by the calligraphy evaluation system, "Kanji" was selected from Founder fonts [17], "Hiragana" was selected from dictionary [18]. "Direction section analysis system" was designed to identify the "Sumi" distribution from different direction. "Font shape recognition system" was applied to identify and evaluate the characteristics of the "Sumi" contour line. The character's contour line was converted to a signal data in order to calculate roundness index and smooth index. "Font shape recognition system" was also quantitative calculated the center of gravity and stability of "Sumi". In the end, the main characteristics between each style were clarified and evaluated by quantitative indicators. Along with writing speed increasing, the "Sumi" distribution showed significant change on vertical direction and diagonal right direction. The roundness index appeared significant difference between four styles. The "Kaisho" presented most smooth contour line comparing other three styles. The centers of gravity of all characters of four styles were concentrated on the center of the framework with stabilization. And four styles of "Kaisho", "Gyosho", "Sousho", "Hiragana" were shown a balance between width of stroke, "Sumi" area and structure stable. 
In a word, the purpose of this study was to establish a quantitative analysis system to evaluate calligraphy work and provided an appreciate software to learner as a reference to help improve their writing skill.

\section{Establishing of Calligraphy Evaluation System}

\subsection{The Synopsis of Calligraphy Evaluation System}

A good calligraphy product requires not only the formal beauty, but also appreciates the beautiful mood. The evaluation method of brush calligraphy originated from China was established and developed in the long course of history and culture. That aesthetical standard has already been consistently rooted into peoples' heart deeply in Asia. "The exquisite truth of calligraphy, first is spiritual charm, second is form and quality, get both the two, can be considered inherited the ancients." wrote Southern Dynasty famous calligraphy theoretician "Wang Sengqian" on "Biyizan". Therefore, there are three key points on evaluation of brush calligraphy, form, quality and spiritual charm. In fact side, "Form" means character of the structure, appearance, layout, blank, center of gravity and other spatial distribution characteristics, which include stroke length, thickness, shades, density. "Quality" means writing skill, brush using technique, line quality, ink changes. The force of "Qibi", "Xingbi", "Shoubi" in each stroke is uniform and smooth. The eight basic elements, "Dian", "Heng", "Zhe", "Shu", "Gou", "Pie", "Na" and "Ti" are required to conform to the writing rules. In virtual side, "Spiritual charm" is a presentation of calligraphy works including imagination, expression and temperamentally.

The calligraphy character evaluated system was proposed and designed to quantitative the calligraphy product based on the evaluation theory of calligraphy. As always, the quality of calligraphy product was evaluated and judged by experienced masters according to their experience and intuition, which is very subjective relied on the evaluators' status and reputation. The new brush character evaluated system was used to establish an evaluation index of synthesis quantify method by numerical method.

The brush calligraphy evaluation system turns the works' characteristics of "Shape" and "Quality" into quantitative indicators, which was consisted of two parts: direction section analysis and font shape recognition system as shown in Fig. 1. The direction section analysis system was divided into two parts: straight section analysis and curved section analysis, which was used to evaluate the distribution of ink. The font shape recognition system was made of six parts, contour line recognition, cut-point identification roundness index calculate, width index calculate, smooth index calculate and ink ratio calculate, which was designed to extract the characteristics of the font shape into numerical index.

\subsection{Direction Section Analysis System}

The brush calligraphy works was expressed with characters by writing brush on "Xuan paper". Artists through adjusting the writing speed and height of brush to control the width and shade of ink during writing process, which was considered most difficult skill for brush calligraphy. During writing process, the line's width of character grows larger when the writing brush was lowered and pushed to the "Xuan paper". The ink was disappeared when the tip of the writing brush leaves the "Xuan paper". Therefore, the direction section analysis system was designed to analyze the distribution of the ink's width from different directions.

The brush calligraphy works was scanned into electronic data as raw preparation. The data of RGB color image were changed to gray image data. The density of "Sumi" was digitized in numerical value from 1 to 255 and is substituted for each element as the property value of the element. Next, the length of the line and balance index of writing brush characters were carried out by direction section analysis system, and the program's analysis process of brush character evaluated system was shown as following: 


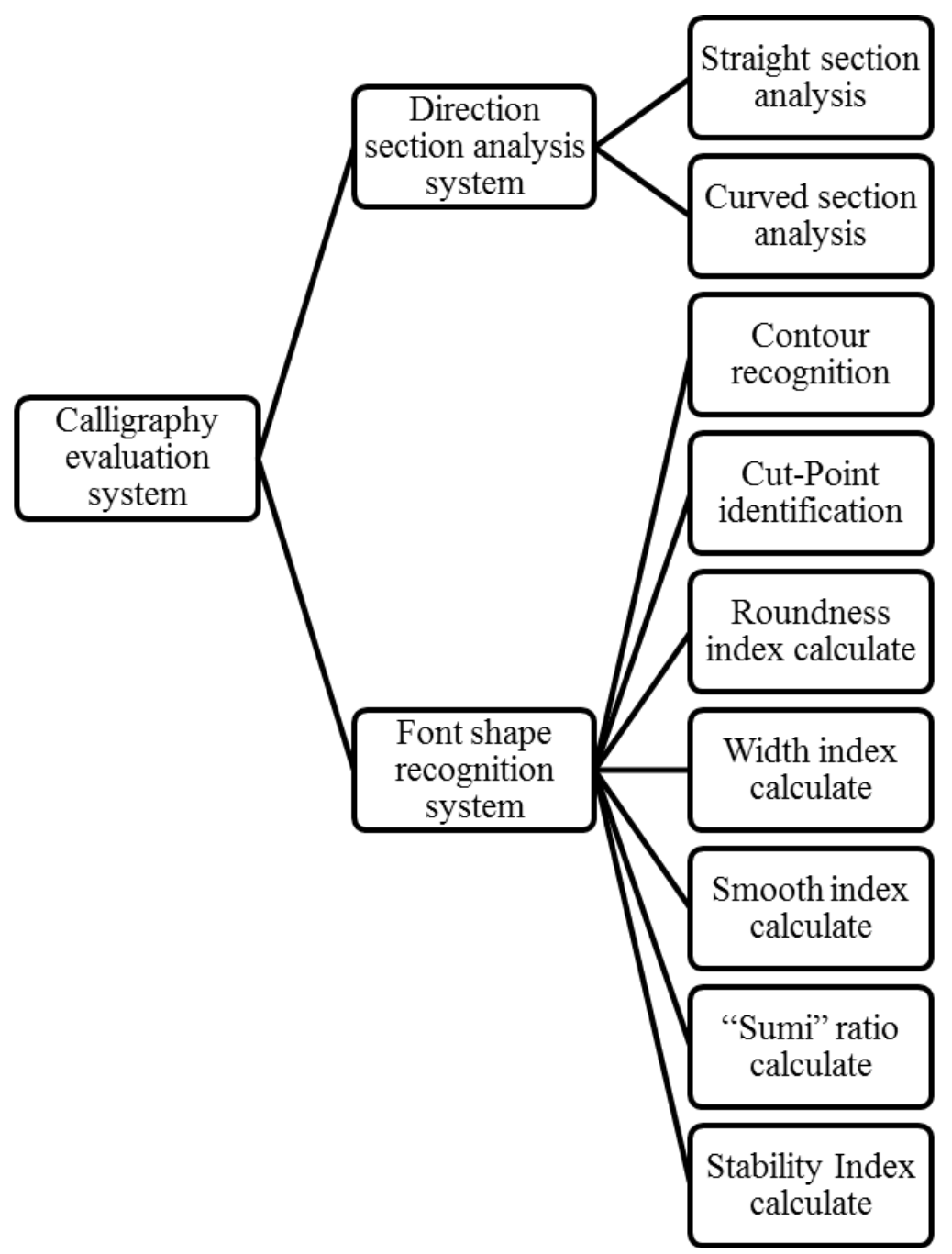

Fig. 1 Flow chart of Calligraphy evaluation system.

(1) Written paper was regarded as two-dimensional plane and is divided into many square elements. The image of written paper was produced by scan machine, all the image data were changed into the same designed size in order to examine the distribution of section length of "Sumi" line (black ink) at any incline angle.

(2) The boundary was taken out between "Sumi" part and blank part. And the data of gray image was changed into write and black colors by binaryzation method ("Sumi" area is 0 , the blank is 255).

(3) The section length of each stroke was scanned and calculated according to the specified direction angle $\theta(\theta=0,15,30 \ldots 150,165)$ as shown in Fig. 2.

(4) The data of "Sumi" distribution on each angle were summarized into four parts as horizontal part $(\theta$ $=0,15,165)$, diagonal left part $(\theta=30,45,60)$, vertical part $(\theta=75,90,105)$ and diagonal right part $(\theta=120,135,150)$.

(5) The weight coefficients of section length of four parts were calculated by Eq. (1)

$$
\text { weight coefficients }=
$$

$$
\begin{gathered}
\mathrm{a} 1 * 1 \mathrm{e}-06+\mathrm{a} 2 * 1 \mathrm{e}-05+\mathrm{a} 3 * 0.0001+ \\
\mathrm{a} 4 * 0.001+\mathrm{a} 5 * 0.01+\mathrm{a} 6 * 0.1+\mathrm{a} 7 * 1+ \\
\mathrm{a} 8 * 10+\mathrm{a} 9 * 100+\mathrm{a} 10 * 1000
\end{gathered}
$$

where "a1", "a2", “a3", “a4”, “a5”, “a6”, “a7”, “a8”, "a9", "a10" were the frequency of section length of each line in range of "1-9", "10-19", "20-29", "30-39", “40-49”, “50-59”, “60-69”, “70-79”, “80-89”, “90-159”. 


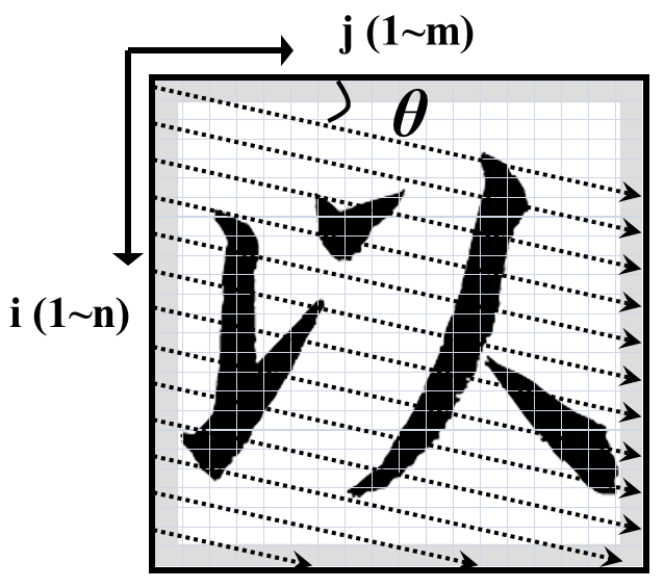

Fig. 2 Scanning direction with angle $\theta$.

\subsection{Font Shape Recognition System}

The magic of brush calligraphy is that it can interpret the abstract beauty as a kind of infinite expressive art. A excellent brush calligraphy word was required high writing technique with perfect combination of the brush contact angle with paper, writing speed, acceleration, and pressure and so on, which was main reason that ink presents design shape with different thickness, length, size, concentration. It goes in for fluent motion during writing process, which needs strength, rhythm and administrative levels. Therefore, the main purpose of the font shape recognition system was to analyze the shape of the font characteristics, and express sensibility evaluation by digital index.

\subsubsection{Contour Line Recognition}

In first part of the contour line recognition, the contour line of font's ink was identified and converts into signal data. As mentioned above the brush calligraphy works was scanned and changed to the grayscale image as preparation data ("Sumi" area is 0 , the blank is 255). The program's analysis process of the part of contour line recognition was explained as following:

(1) The contour line was identified and taken out from ink area by linking the element between "Sumi" part and blank part. And the data of contour line were marked discriminate between ink area and blank area.

(2) The ink element did not contact with the blank area in 4 adjacent elements of up, down, left, right (Part a, Part b, Part c, Part d), was deleted and changed into blank area as shown in Fig. 3. And the blank element did not contact with the ink area in 4 adjacent elements of up, down, left, right (Part a, Part b, Part c, Part d), was also deleted and changed into ink area.

(3) The contour line was explored by program depth search through depth-first search algorithm. The contour line was converted into a set of signal data according to the direction information of search path. During the search process, search direction turn left was marked as a negative number, and turn right was marked as positive number. Compared with parent
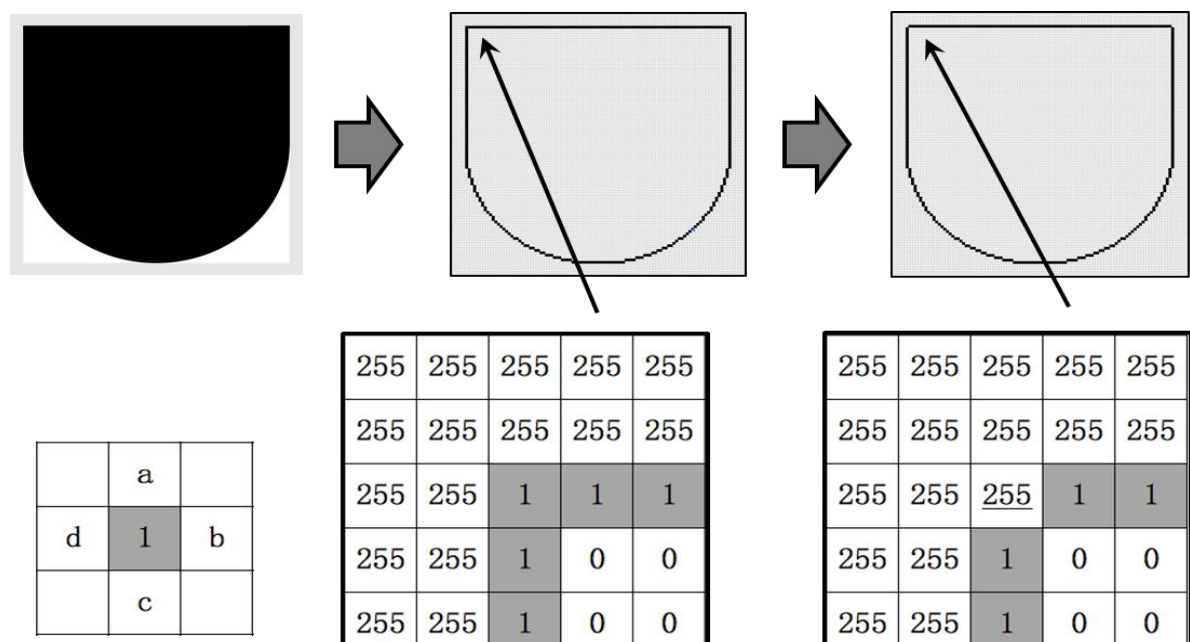

\begin{tabular}{|c|c|c|c|c|}
\hline 255 & 255 & 255 & 255 & 255 \\
\hline 255 & 255 & 255 & 255 & 255 \\
\hline 255 & 255 & 1 & 1 & 1 \\
\hline 255 & 255 & 1 & 0 & 0 \\
\hline 255 & 255 & 1 & 0 & 0 \\
\hline
\end{tabular}

\begin{tabular}{|c|c|c|c|c|}
\hline 255 & 255 & 255 & 255 & 255 \\
\hline 255 & 255 & 255 & 255 & 255 \\
\hline 255 & 255 & $\underline{255}$ & 1 & 1 \\
\hline 255 & 255 & 1 & 0 & 0 \\
\hline 255 & 255 & 1 & 0 & 0 \\
\hline
\end{tabular}

Fig. 3 Contour line extraction process. 


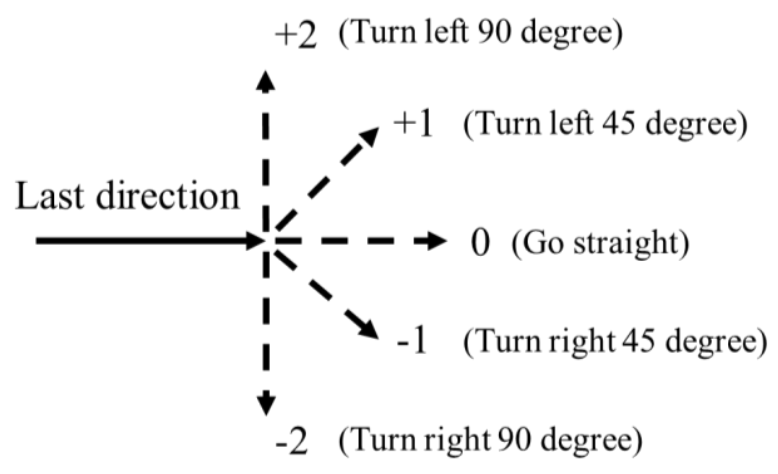

Fig. 4 Signal data determination.

direction, the child direction was record into $0,1,2$, when direction change were $0,45,90$ degrees as shown in Fig. 4 (Parent direction: the direction of current node to child nodes; Child direction: the direction of parent node to the current node). An example of signal data trace interpreted from contour line was shown in Fig. 5.

\subsubsection{Cut-Point Identification}

The line of calligraphy was crossed combination under the premise of Chinese characters form and stroke order principle. The beauty of calligraphy was shown directly by the line of calligraphy. Identifying cut-point was one of the important steps for evaluation of the line of calligraphy. According to the part of contour line recognition, the direction information of contour line was converted to a data signal. The vertex of stroke was the point where the direction of contour line was drastic change during a short limited distance. The limited distance was defined according to the size of image. In this research, all images were unified into the same size as $110 * 110$ pixel. The limited distance was defined by five pixels, where the direction of contour line was changed over ninety-degree in this research. The sum of three consecutive direction signal data greater than 2 was considered as a vertex in of calligraphy. Therefore, in this study, there are 24 kinds of cases that can be defined as the vertices, which were listed as shown in Fig. 6. The two examples were presented in Figs. 7 and 8. According to Figs. 7 and 8, the vertexes were extracted from signal data corresponding to image data commendably.

\subsubsection{Roundness Index Calculate}

Calligraphy is an abstract painting consisted by points and strokes. A good calligraphy can present a picture of artistic conception, which is reflected calligrapher's aesthetic pursuit. In other words, Calligrapher creates painting to form the whole artistic conception by using by points and strokes. Points and strokes are also the important factor to distinguish font style. The powerful feeling is very important in the aesthetic system of China. The powerful points or strokes can give a person with aesthetic feeling. This powerful feeling was concluded and judged as two elements of "Yuan" and "Se". "Yuan" is a smooth
(1) (2)

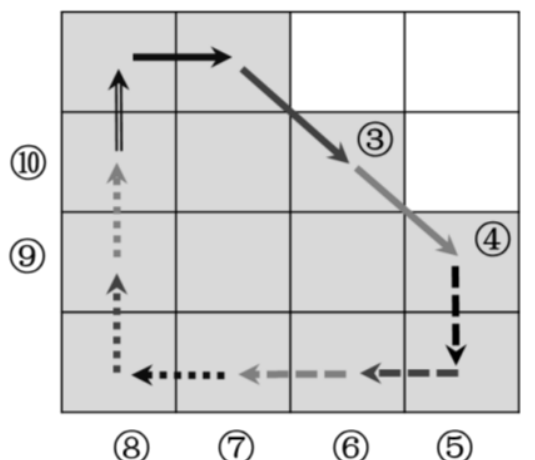

(8) (7) (6) (5)

\begin{tabular}{|c|c|c|c|}
\hline No. & Next direction & Last direction & Signal data \\
\hline (1) & $\longrightarrow$ & No & 0 \\
\hline (2) & $\longrightarrow$ & $\longrightarrow$ & -1 \\
\hline (3) & $\longrightarrow$ & $\longrightarrow$ & 0 \\
\hline (4) & -ー-ー $\rightarrow$ & $\longrightarrow$ & -1 \\
\hline (5) & 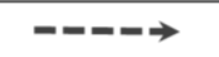 & -ーーー & -2 \\
\hline (6) & -ーーー & -ーー- $\rightarrow$ & 0 \\
\hline (7) & (n...... & -ーーー & 0 \\
\hline (8) & (......... & (........ & -2 \\
\hline (9) & (........, & (........., & 0 \\
\hline (10) & $\Longrightarrow$ & (........ & 0 \\
\hline
\end{tabular}

Fig. 5 Example of signal data trace of contour line. 


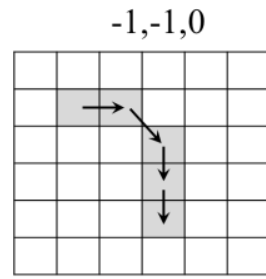

$-2,0,-2$

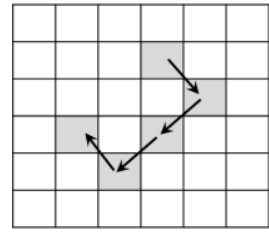

$-1,-2,0$

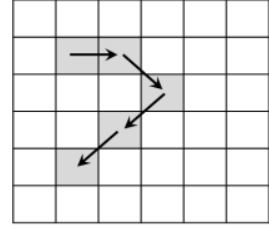

$-2,0,-1$

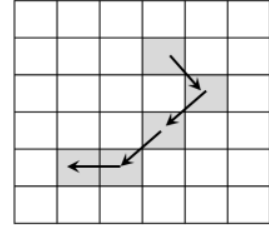

$0,-2,0$

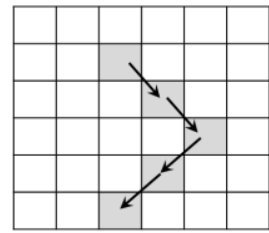

$-1,-1,-1$

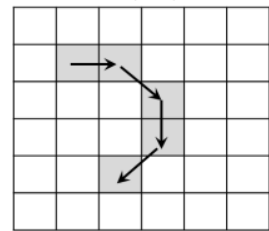

$1,1,0$

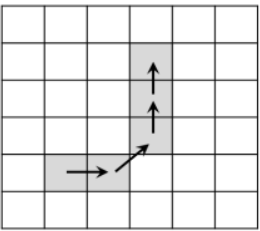

$2,0,2$

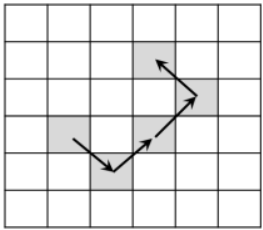

$1,2,0$

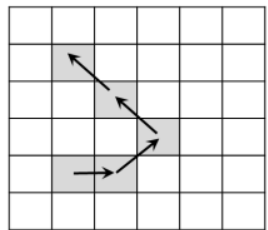

$2,0,1$

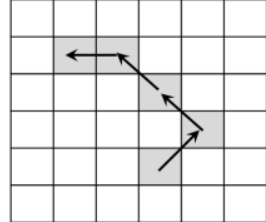

$0,2,0$

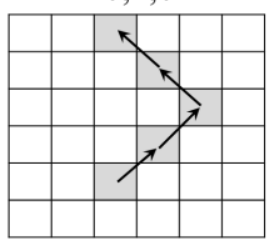

$1,1,1$

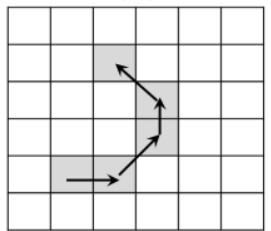

$0,-1,-1$

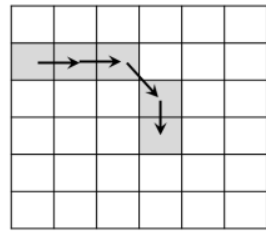

$-2,-1,0$

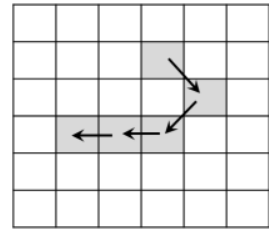

$-1,2,-1$

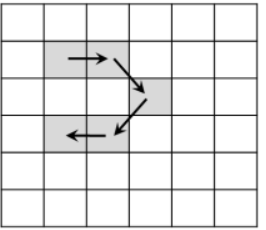

$-1,0,-2$

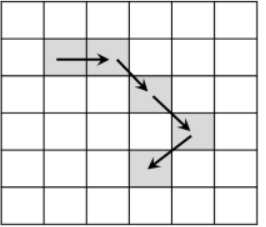

$-1,-1,-2$

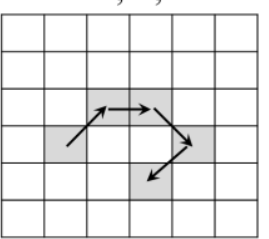

$-2,-1,-1$

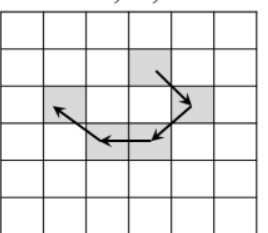

$1,1,0$

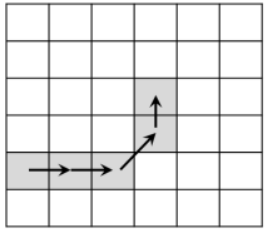

2,1,0

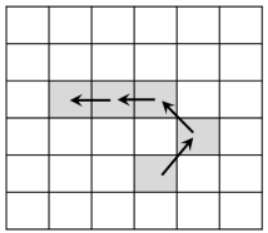

$1,2,1$

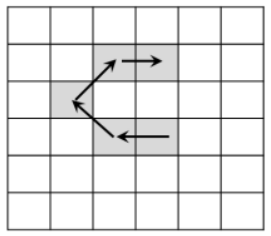

$1,0,2$

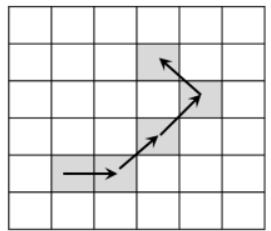

$1,1,2$

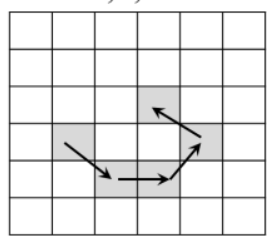

2,1,1

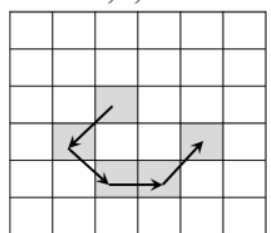

Fig. 6 Twenty-four kinds of situation for cut-point identification.

stereoscopic concept. Through the full, strong, relief points and strokes to show a powerful force. The concept of "Se" is a non-smooth feeling. It is ink (points and strokes) break through the resistance of the paper during writing process, a kind of artistic effect of struggling. The points and strokes show powerful sense when they met this kind of obstruction from paper and overcome it. To put it simply, the roundness of points and strokes is one of the most important criteria of calligraphy evaluation.

Building on the theories above, the vertex was identified from signal data. The contour line was divided into several segmental lines by vertexes, which were supposed to be curved line with radian. The roundness index was calculated by Eq. (2). The validation case was shown in Fig. 9. According to the Fig. 9, the roundness index reflected the radian level of ink. 

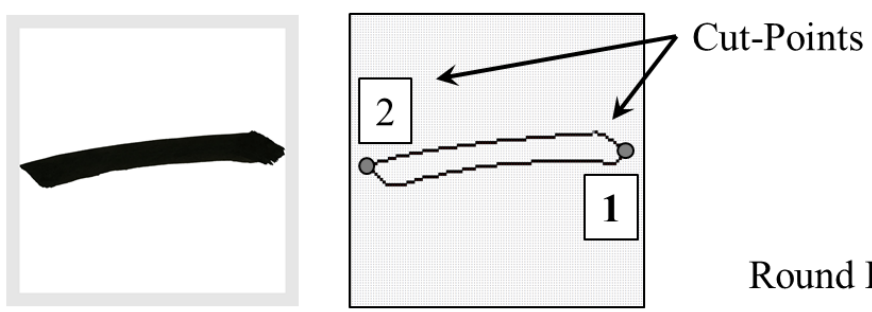

Round Index $=12.53$

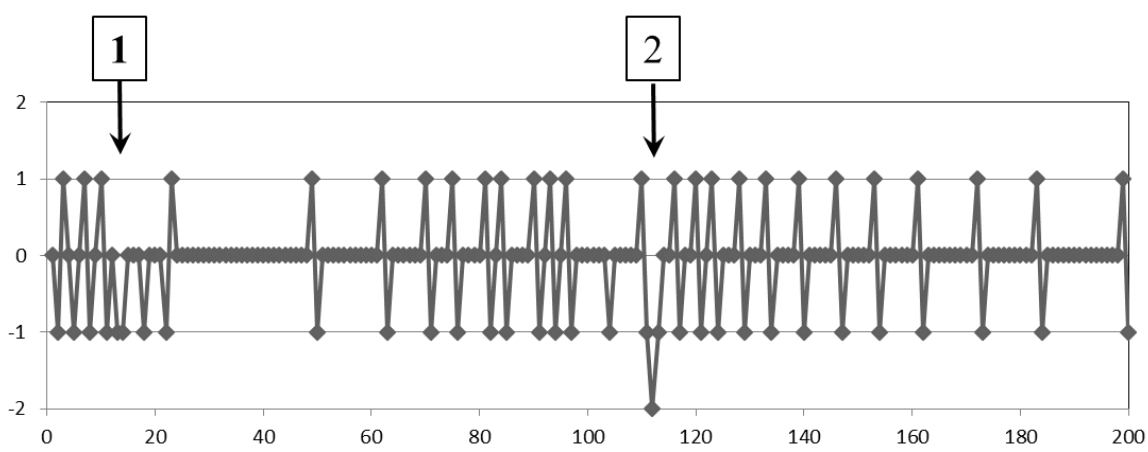

Fig. 7 Cut-point identification example of horizontal stroke.
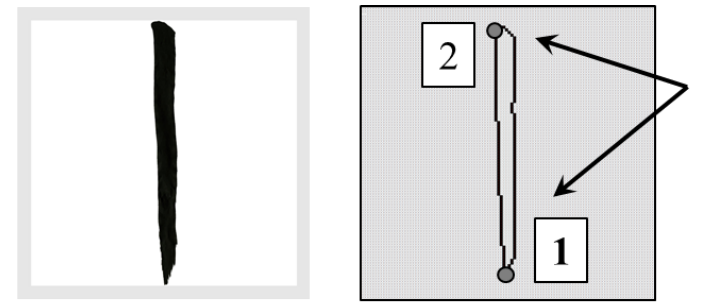

Cut-Points

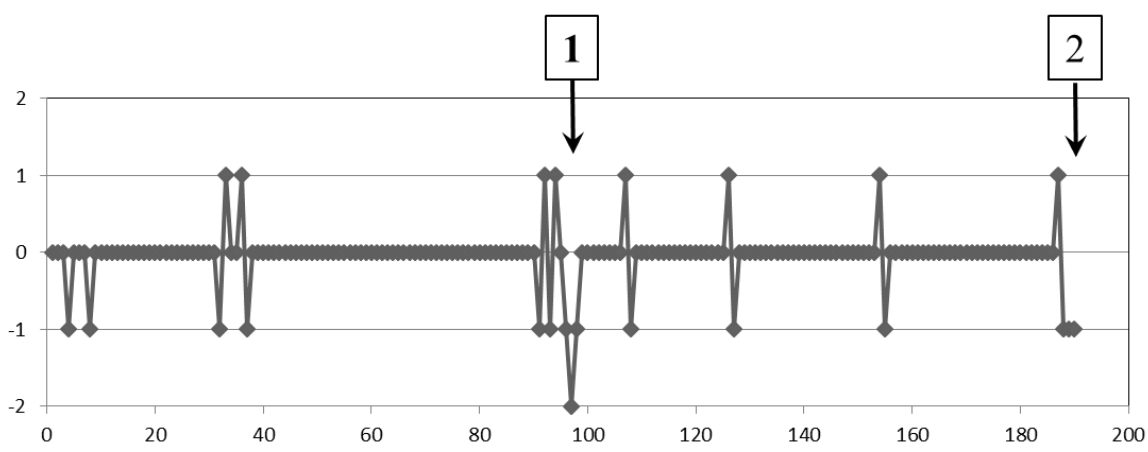

Fig. 8 Cut-point identification example of vertical stroke.

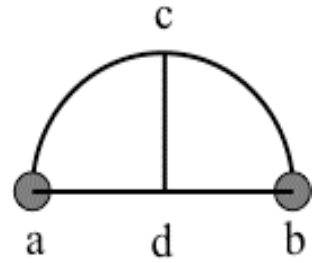

Roundness index $=\sum_{1}^{n} \frac{\widehat{a c b}}{\text { Maxacb }} \times \frac{c d}{a b}$

where "a", "b" were cut-point on contour line. The "ab" was linear distance between two points "a", "b". The "acb" was the track length of the contour line between "a", "b". The "max-acb" was the longest track length in this character font.

2.3.4 Width Index, Smooth Index and Ink Ratio

Normally, there is a training process of calligraphy from easy to difficult, beginner practices "Kaisho" firstly, and practice "Gyosho" secondly, finally contact with "Sousho" and "Hiragana". The biggest difference between "Kaisho", "Gyosho" and "Sousho" lies in the writing speed and writing coherence. Normally, the width 
A

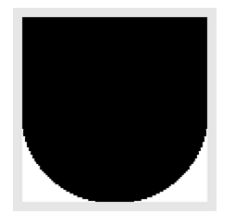

$\mathrm{D}$

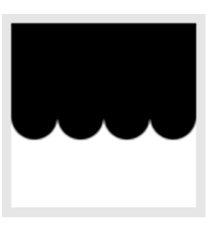

B

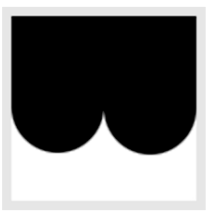

E

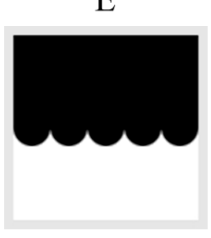

C

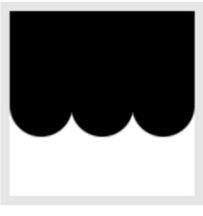

$\mathrm{F}$

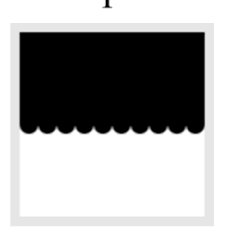

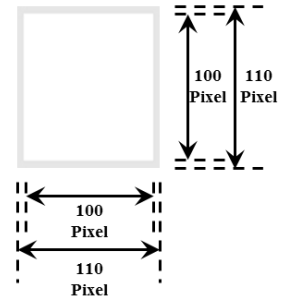

E $\quad$ F

\begin{tabular}{lllllll}
\hline $\begin{array}{c}\text { Round } \\
\text { Index }\end{array}$ & 222.54 & 122.59 & 82.40 & 58.52 & 41.60 & 17.73 \\
\hline
\end{tabular}

Fig. 9 Verification of roundness index calculation.

of lines, smooth of contour line and ink ratio will be changed and reflected with writing speed. Therefore, width index, smooth index and "Sumi" ratio was focused in this research, which was calculated by Eqs. (3)-(5).

$$
\text { Width index }=\frac{\text { "Sumi" area }}{\text { The lengt } h \text { of the contour line }}
$$

\section{Smooth index $=$}

The number of 0 among Signal data

The number of Signal data

$$
\text { "Sumi" ratio }=\frac{\text { "Sumi" area }}{\text { Framework area }}
$$

\subsubsection{Stability Index}

The calligraphy character can be ever-changing, and writing performance skills can be varied, but it must be hold the center of gravity stability as standing on the ground. The structure of the font can be separated, but the center of gravity could not leave the ground, which is the foundation of the calligraphy writing. Some beginners' products, lying down on the paper seems to be overcautious balance, but if standing up the paper, tends to be stagger and unstable. This theory also applies to Japanese "Hiragara" writing. There is a sentence about calligraphy evaluation in Japan, "The left is only just white paper, but heaven and earth are born at the moment when a writer is going to write a character, and gravity begins to work like the right." (Ishikawa: Sho, 2005) The center of gravity was calculated by Eq. (6). And the stability index was proposed and designed according to this evaluation method in this study, which was calculated according to Eq. (7). The bottom of the "Xuan" paper was seen as the earth, and the top of "Xuan" paper was considered as the sky. The calligraphy was more stable when the whole elements closer the bottom of "Xuan" paper.

$$
\begin{gathered}
Y_{i}=\frac{\sum_{i=1}^{N}(i-0.5)}{N} \\
Y_{j}=\frac{\sum_{j=1}^{N}(j-0.5)}{N}
\end{gathered}
$$

where "Yi" and "Yj" were coordinates of the center of gravity. "N" was the number of "Sumi" pixel. "i", “j” were vertical coordinate and horizontal coordinate as shown in Fig. 2.

$$
\begin{gathered}
J_{g} \geq \frac{m}{2} \\
S_{I}=\frac{V}{n m}\left\{\left(1-\frac{I_{g}}{n}\right)+\alpha\left(1-\frac{J_{g}}{m}\right)\right\} \\
J_{g}<\frac{m}{2} \\
S_{I}=\frac{V}{n m}\left\{\left(1-\frac{I_{g}}{n}\right)+\alpha\left(\frac{J_{g}}{m}\right)\right\}
\end{gathered}
$$


where "SI" was stability index. " $n$ ", "m" were height and width of framework. "Ig" and "Jg" were coordinates of center of framework. "V" was "Sumi" area of character. The value of " $\alpha$ " was 0.5 .

\section{Application of Calligraphy Evaluation System}

\subsection{Three Kinds of "Kanji" and "Hiragana"}

During their long history of development, Chinese characters have evolved into many different script forms, such as the seal character, official script, Kaisho, Gyosho and Sousho. Japanese have formulated some native characteristic forms, "Hiragana". In this research, three kinds of Chinese "Kanji" and Japanese "Hiragana" were analyzed by calligraphy evaluation system, which was designed to obtain a quantified analysis of this evolution. The three types of Chinese "Kanji" of "Kaisho", "Gyosho", "Sousho" and Japanese "Hiragana" were compared according to the order of calligraphy training process. The characteristics of "Sumi" length distribution and shape structure were calculated by direction section analysis system font shape recognition system in order to establish a quantitative evaluated benchmark.

The representative fonts that have been widely accepted by the people were considered and selected in order to scientific reasonable evaluate benchmark parameter and establish numerical reference standard system.

In this research, the 47 "Hiragana" of "Iroha" were focused 3 kinds of "Kanji” styles, "Kaisho", "Gyosho", "Sousho", and were analyzed to compare with "Hiragana", each one character of calligraphy character from "Iroha" poem was taken up in this research as shown in Figs. 10-12. Forty-seven "Hiragana" characters were shown in Fig. 13. "Iroha" poem was a famous song in Japan. It can date back to written during 11th century. It is a perfect pangram and an isogram, containing each character of the Japanese syllabary exactly once. Because of this, it is also used as an ordering for the syllabary. This poem has the characteristic made without repeating 47 "Hiragana" characters, which is the song of Buddhism-like mutability. The author of this song is missing. This poem has been used as a "Hand-book" for Japanese to do writing practice hiragana since 11 century. "Iroha" poem translated into English was quoted from the site of "Watanabesato". All 3 kinds of "Kanji" styles were adopted from computer calligraphy font designed by Founder, Founder is the largest developer of Chinese fonts. More than $90 \%$ of Chinese newspapers and publishers worldwide use Founder fonts. The "Hiragana" calligraphy characters were adopted from the dictionary [18].

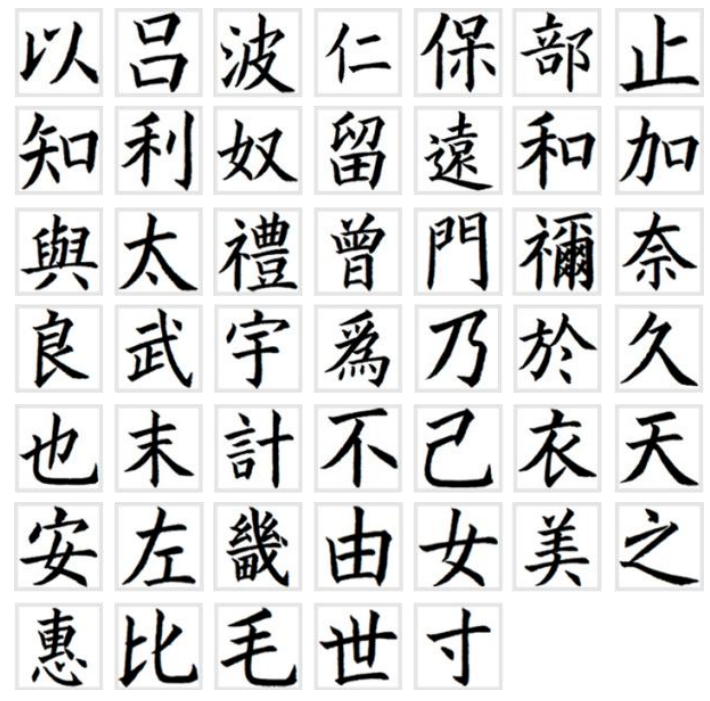

Fig. 10 Forty-seven characters of "Kaisho".

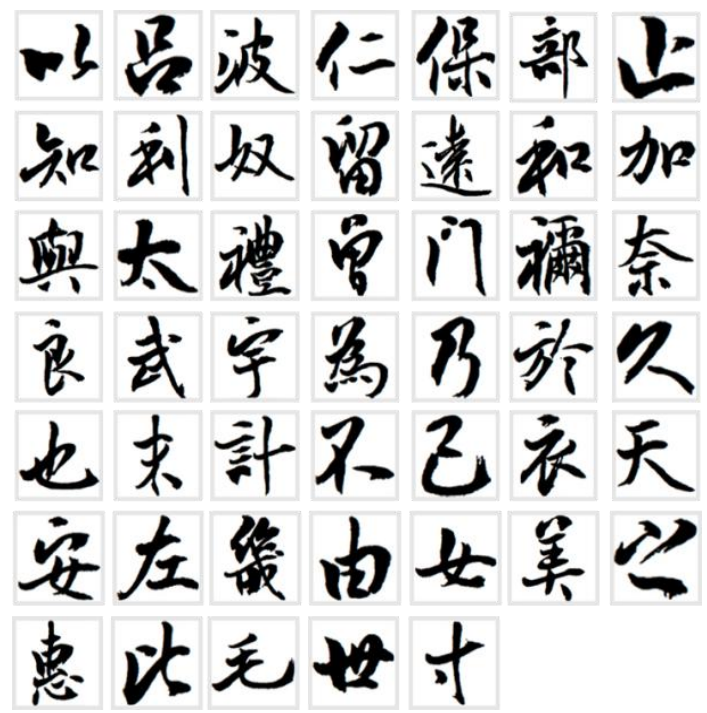

Fig. 11 Forty-seven characters of "Gyosho". 


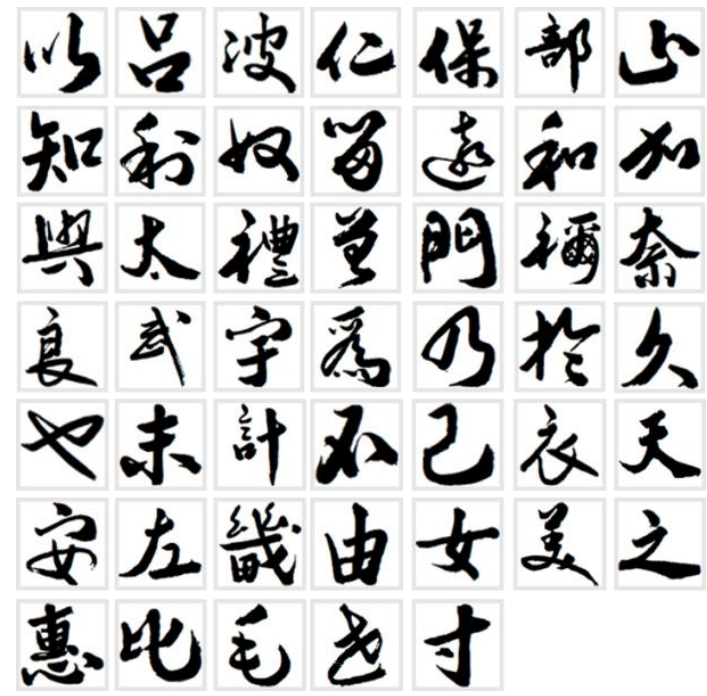

Fig. 12 Forty-seven characters of "Sousho".

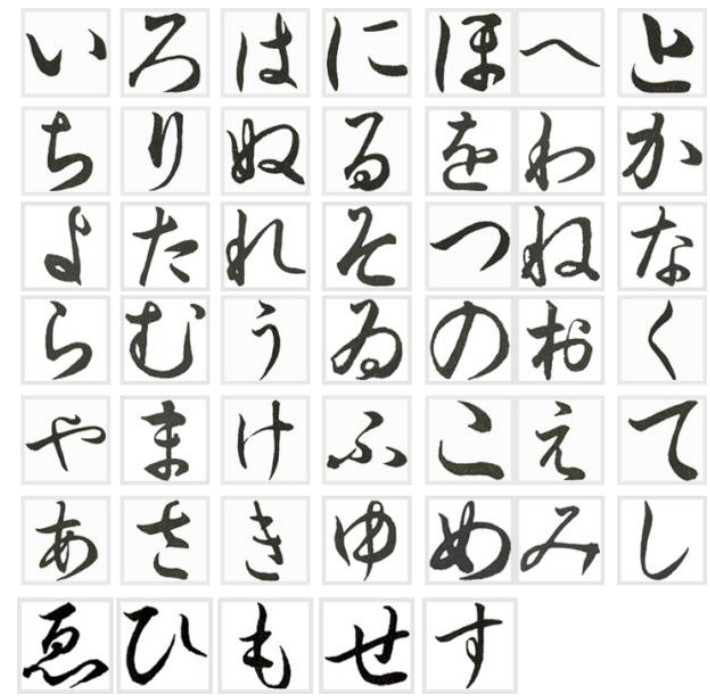

Fig. 13 Forty-seven characters of "Hiragana".

\subsection{Result of Direction Section Analysis}

As mentioned above, 188 characters were analyzed by direction section analysis from 12 directions. (Angle $\theta=0,15,30 \ldots 150,165$ ) The results of 0,15 , and 165 degrees were relegated to the horizontal part. The results of 30, 45 and 60 degrees were relegated to the diagonal left part. The results of 75, 90 and 105 degrees were relegated to the vertical part. The results of 120,135 and 150 degrees were relegated to the diagonal right part. Here illustrated “以” (“い”) character as a example in Fig. 14. Fig. 14 showed the frequency distribution results of the sectional pixel number corresponding to each direction.
The "Kaisho" of "以" presents longer sections in the range to $40-49,50-159$ on vertical part and diagonal right part. It is because each stroke of "Kaisho" was standardized and written out step by step. The character of "以" was consisted by one "Ti", two "Dian", "Pie", in which the most longest stroke was "Pie" on diagonal right part. In case of "Gyosho" of "以", with the speeding up of using brush, the first stroke "Ti" and second stroke "Dian" showed connection, and the third stroke "Pie" and forth stroke "Dian" also showed connection. It was appeared the trend of truing left in overall. The section of character present shorter in vertical direction and wider in horizontal direction comparing with "Kaisho". Therefore, four parts' distributions were shown large and similar frequency in range 1-9, 10-19, 20-29, 30-39, 40-49. And the largest range 50-159 was concentrated on horizontal part and diagonal left part.

In next case, "Sousho" had the fastest brush using speed compared with above two kinds of style during writing process. The first stroke "Ti" became "Dian", which had shorter stroke path. The width of second "Dian" became thinner, and its length became longer. It means that the brush was taken a less time to stay on paper. The third stroke "Pie" and forth stroke "Dian" became one stroke directly, which was not connected two strokes. It is easy to find that the "Sumi" was concentrated in last stroke on vertical part and diagonal right part. Only diagonal right part was illustrated in range of 50-159, and vertical part was shown large frequency in range 40-49.

"Hiragana" was simplified from "Kanji". The character “๘” was originated from “以”, which the four strokes of became two strokes. The whole character remained level, but all radicals rotated to the left, which were consistent with the measured data, the large frequency of range of 50-159 was displayed on diagonal left part and vertical part.

Above all, through the calculation of the direction section analysis system, the "Sumi" distribution characteristics of "Kanji" and "Hiragana" characters can be clearly reflected quantitative indicators. 

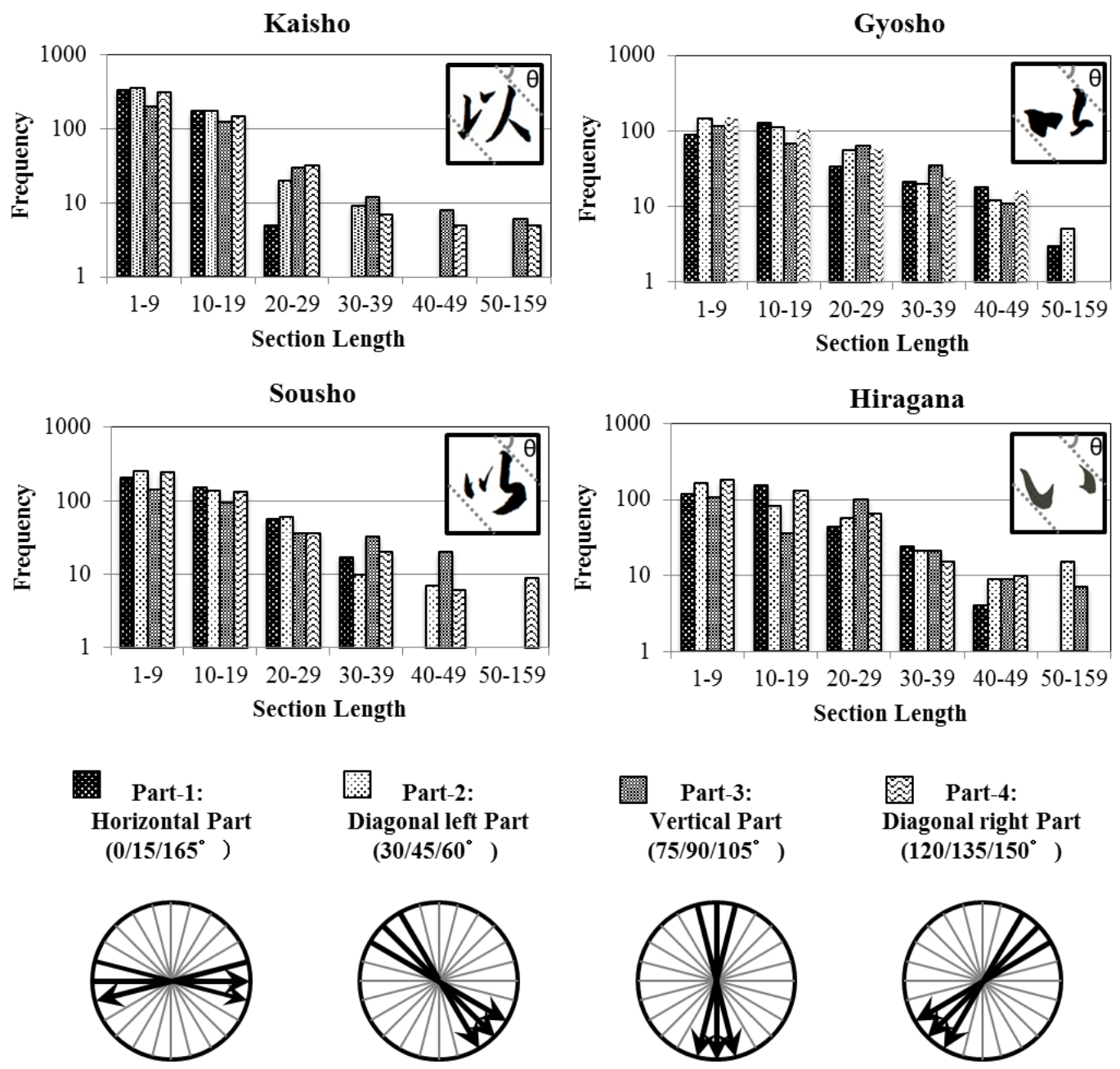

Fig. 14 Distribution results of "Kanji” of “以” (“い”).

In Fig. 15 average weight coefficient of section length index of horizontal part, diagonal left part, vertical part and diagonal right part were summarized by 47 characters. As well known, "Kanji" calligraphy exercise for beginner started from "Kaisho" to "Gyosho" and then "Sousho" in the end. Along with this calligraphy exercise learning sequence, learner's skill is required of quicker and quicker writing speed and smooth connection by some radical of character. According to Fig. 13, comparing with other two styles, "Sousho" indicated higher average section length in any direction part, especially in vertical and diagonal right part, which showed highest section length value as twice of horizontal and diagonal left part. It suggested that combined stroke parts in "Sousho"

writing style frequently existed in vertical and diagonal right part. Thus in these two direction parts section lengths were dramatically longer. Japanese "Hiragana" was simplified from "Kanji" and transformed from "Sousho" style. Therefore original writing strokes become less as a whole and formed a slim long stroke along with a certain direction. As shown in Fig. 13, previous experience knowledge was verified quantitatively, "Hiragana" exhibited comparable much longer section length in vertical part and diagonal right part for the whole writing arrangement.

\subsection{Result of Font Shape Recognition Analysis}

Applied with roundness index equation, average 


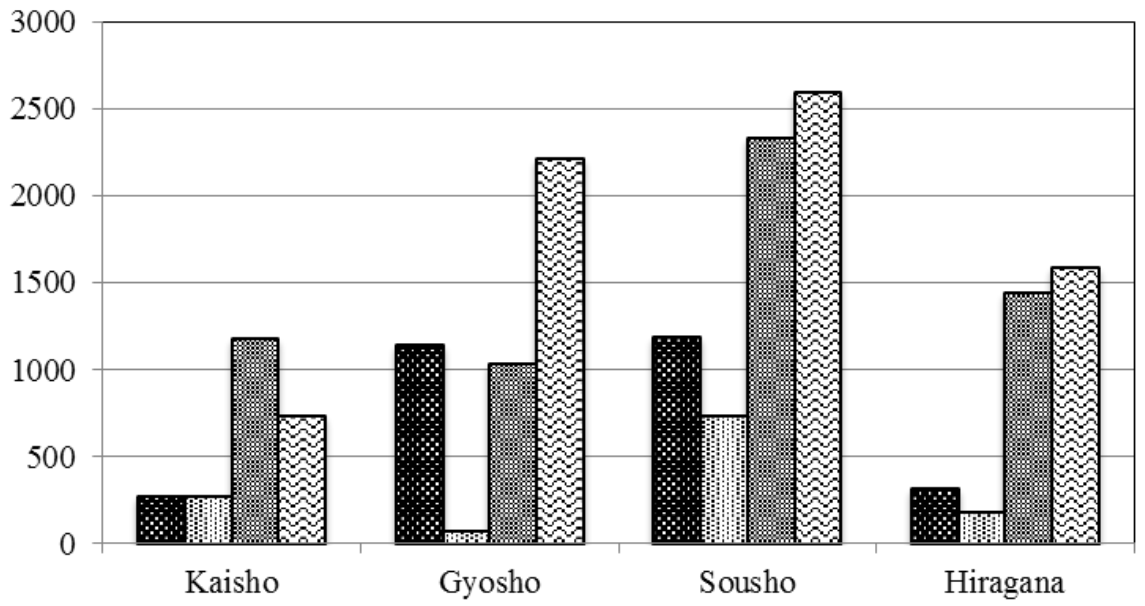

․

Fig. 15 Four parts result of average weight coefficient of section length.

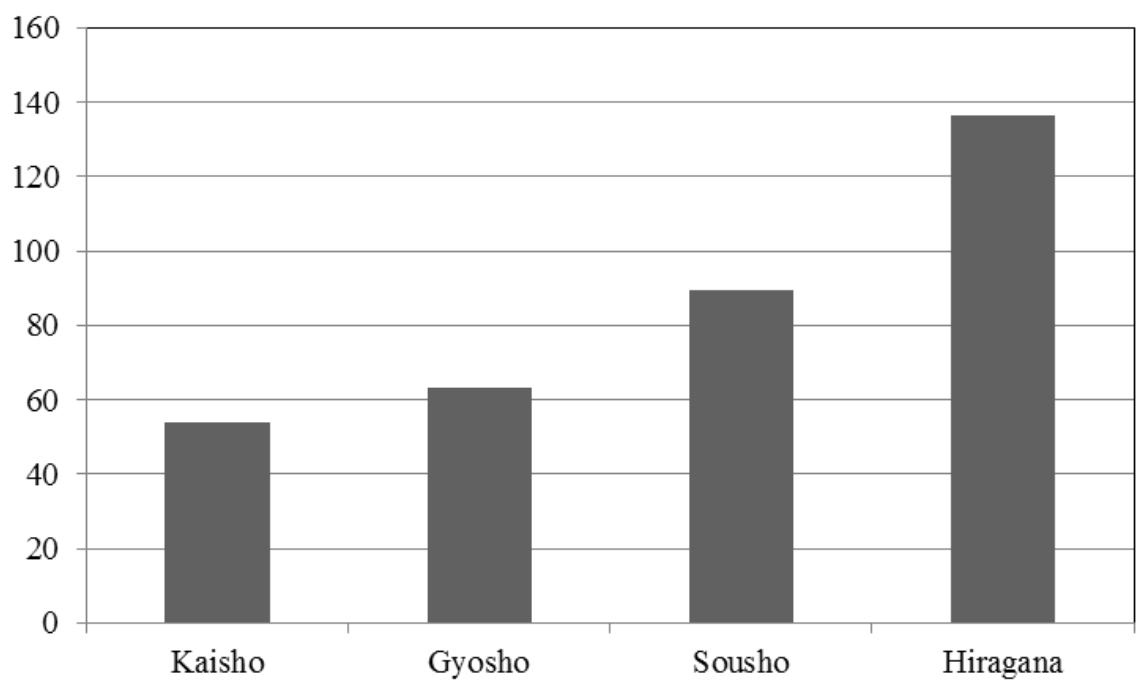

Fig. 16 Average roundness index.

roundness indexes for "Kaisho", "Gyosho", "Sousho" and "Hiragana" of 47 characters were calculated and compared in Fig. 16. It is well known that "Kaisho" is written stroke by stroke with straight line in order to build a square structure in horizontal even vertical open feeling. On the contrary, "Hiragana" smoothly writing style with rounded edge was also impressed on our mind. The roundness data result in Fig.16 achieved the agreement in cognitive knowledge, which "Hiragana" showed the largest value than other three kinds of "Kanji", and "Kaisho" type was the lowest of all. Furthermore, overall 47 characters roundness results for "Kaisho", "Gyosho", "Sousho" and "Hiragana" were plotted in Fig. 17 with ascending sequence from lowest to highest. According to the detailed plotting data and curve in Fig. 17, it is deserved to note that roundness value was increased with increasing combined strokes existence in "Sousho" referring to "Kaisho" form. Additionally, after writing strokes simplification, "Hiragana" type performed a fluently combined strokes which indicated a superior larger roundness index value of all.

The width index was the ratio of the number of 


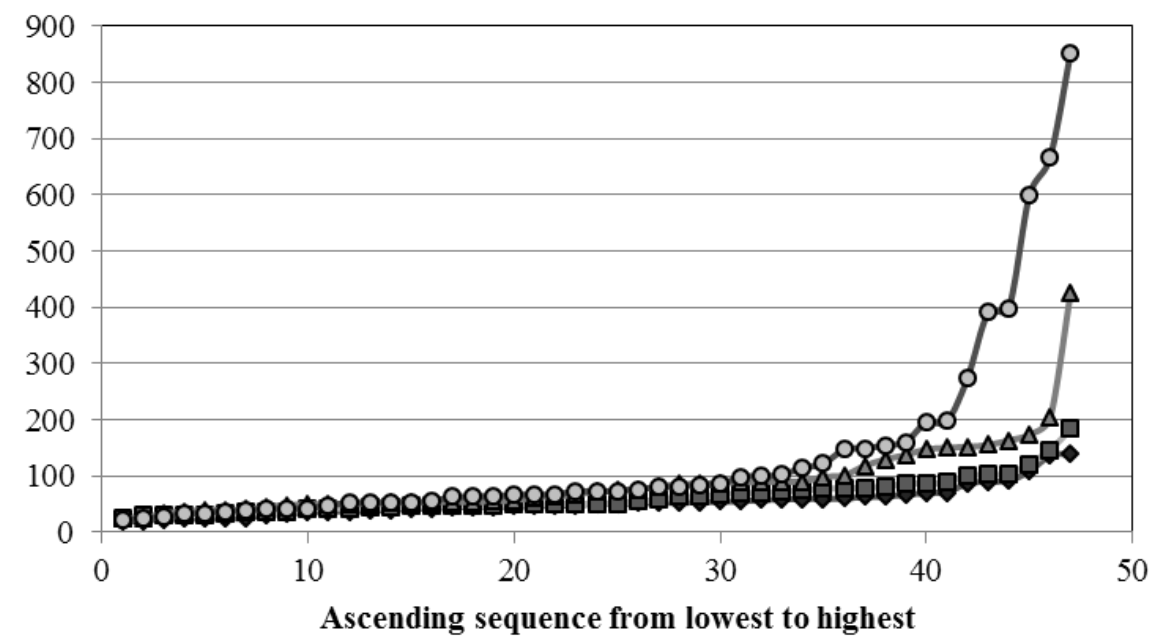

$\leadsto$ Kaisho $\square-$ Gyosho $\quad \Delta$-Sousho - -Hiragana

Fig. 17 The distribution of roundness index.

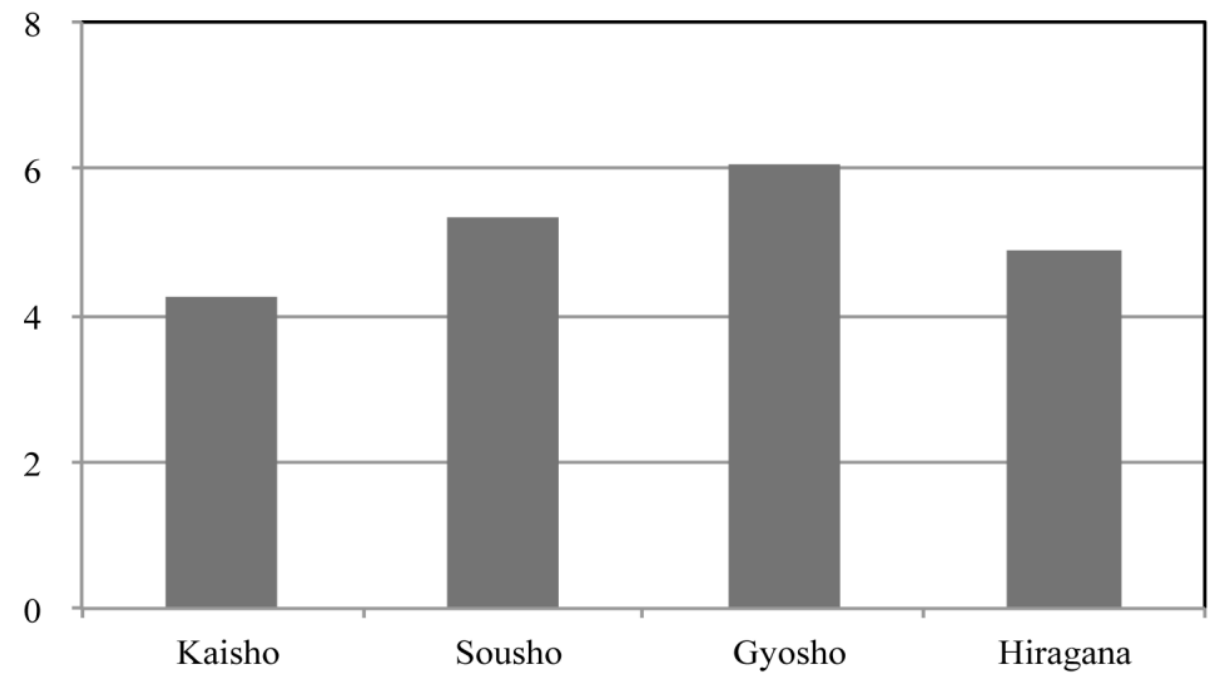

Fig. 18 Average width index.

"Sumi" pixels to the number of the contour line's pixels, which can reflect the width of character's strokes in overall. The averages of width index of 47 characters for each style were calculated and summarized in Fig. 18. As shown in Fig. 18, the width indexes of "Kaisho", "Gyosho" and "Sousho" were 4.24, 5.35 and 6.04. It means that the width of strokes got more and more wider as the writing speed fast. The "Hiragana" was also presented low width index, only larger 0.63 than "Kaisho". Furthermore, there was a similarity between "Kaisho" and "Hiragana".
The each stroke of "Kaisho" was written step by step without connection, the tip of brush did not have large ups and downs during writing process. Although "Hiragana" was simplified "Kanji", which the form was inspired and inherited from "Gyosho" and "Sousho", each part of the character was almost consisted of a complete line. Therefore, this result showed the relationship between writing method and the width characteristics of the stroke.

Interpreted from written character's shape, smooth index characterized by signal data " 0 " (indicated 
stroke moving keeping the same direction as original one) were summarized by 47 characters and compared in Fig. 19. Smooth index described the smooth level of character word's contour line, larger smooth index data indicate more fluent writing work without irregularity contour line condition. As shown in Fig. 19 , the ratio of "signal 0 " to the overall signal data was compared. It is noted that smooth index levels among "Kaisho", "Gyosho", "Sousho" and "Hiragana" were similar. And "Kaisho" just revealed a little bit higher than any other three written styles. Kaisho is composed of many straight stroke lines thus stroke moving direction was comparable stable without turning variable angles, which was able to keep a smoother writing contour line for character.

The "Sumi" ratio was the ratio of the number of "Sumi" pixels to the number of the quartet framework $\left(110^{*} 110\right)$, which was used to measure the area of the "Sumi" within the framework of the same size. The result of "Sumi" ratio was shown in Fig. 20. According to Fig. 20, "Kaisho", "Gyosho" and "Sousho" had shown increasing average "Sumi" ratio of 47 characters, were $0.209,0.233$ and 0.252 respectively. As previously mentioned, "Hiragana" had

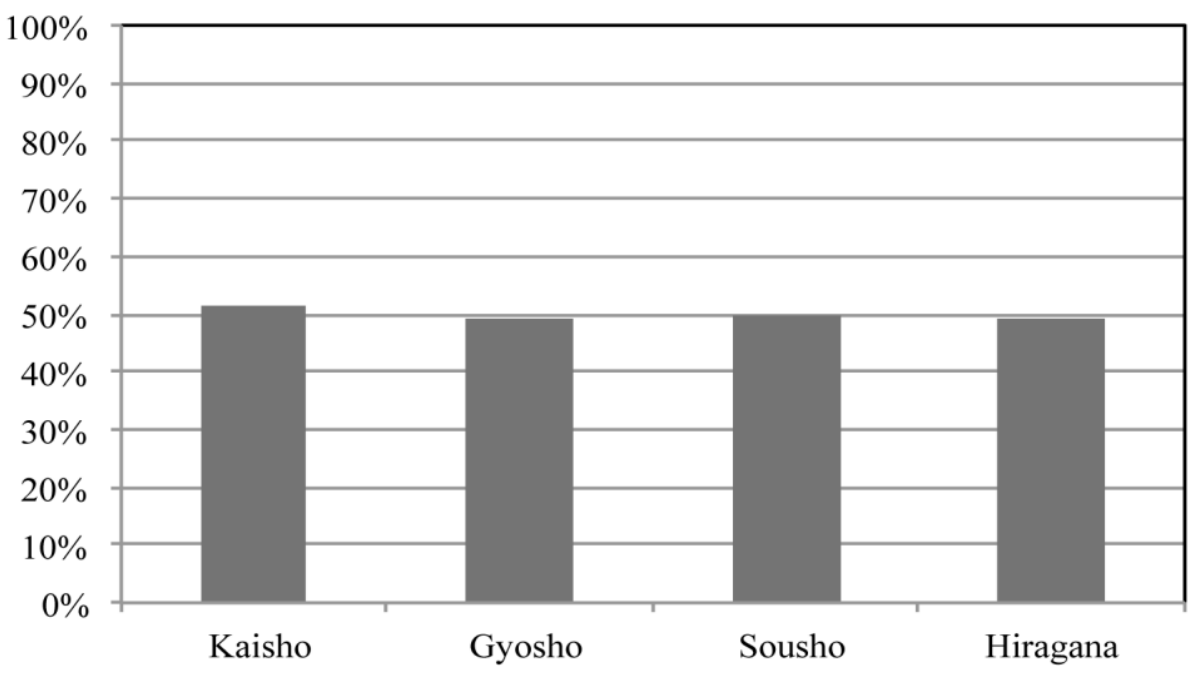

Fig. 19 Average smooth index.

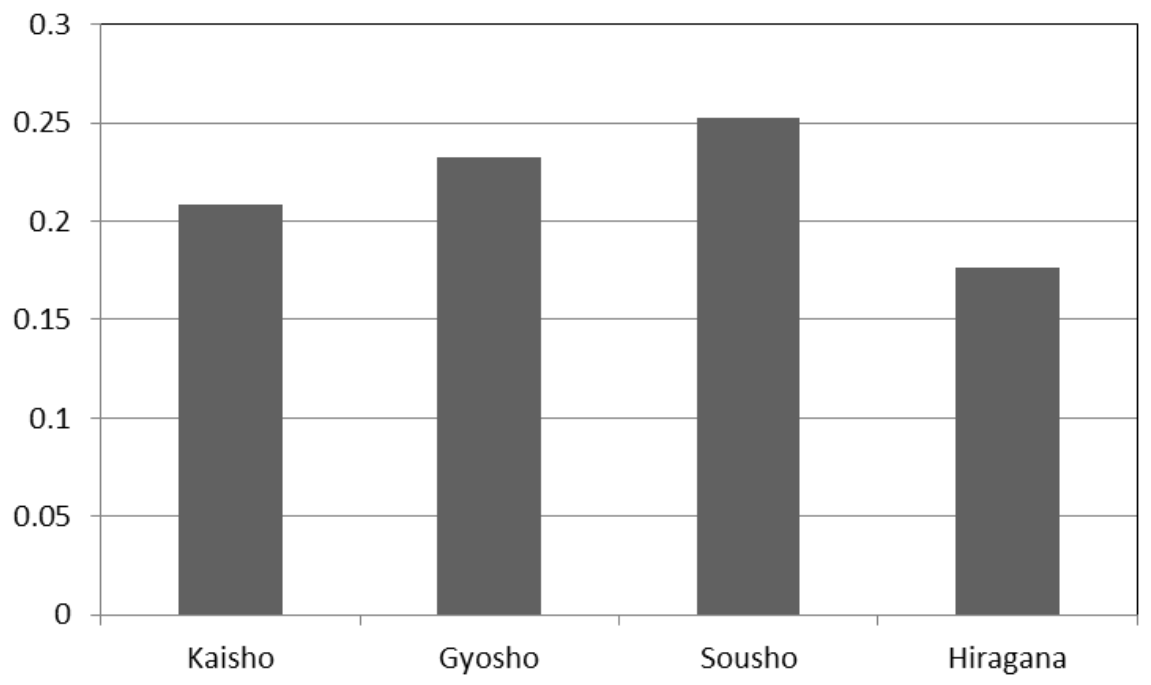

Fig. 20 Average "Sumi" ratio. 
similar width index with "Kaisho", but the number of strokes of "Hiragana" was less than "Kaisho". Therefore, the average "Sumi" ratio also less than "Kaisho" was 0.176 .

The 47 characters' center of gravity of four styles was illustrated in Fig. 21. These $188(47 * 4)$ characters were selected from computer and dictionary with wide recognition and reception. According to Fig. 21, no matter how the shape, structure and style change, center of gravity of character will be located on controlled location, " $\mathrm{i}$ " around 40 to 70 and " $\mathrm{j}$ " around 45 to 70, which located at light right side of center of framework. The stability index was calculated and summarized on Fig. 22. Under the precondition of

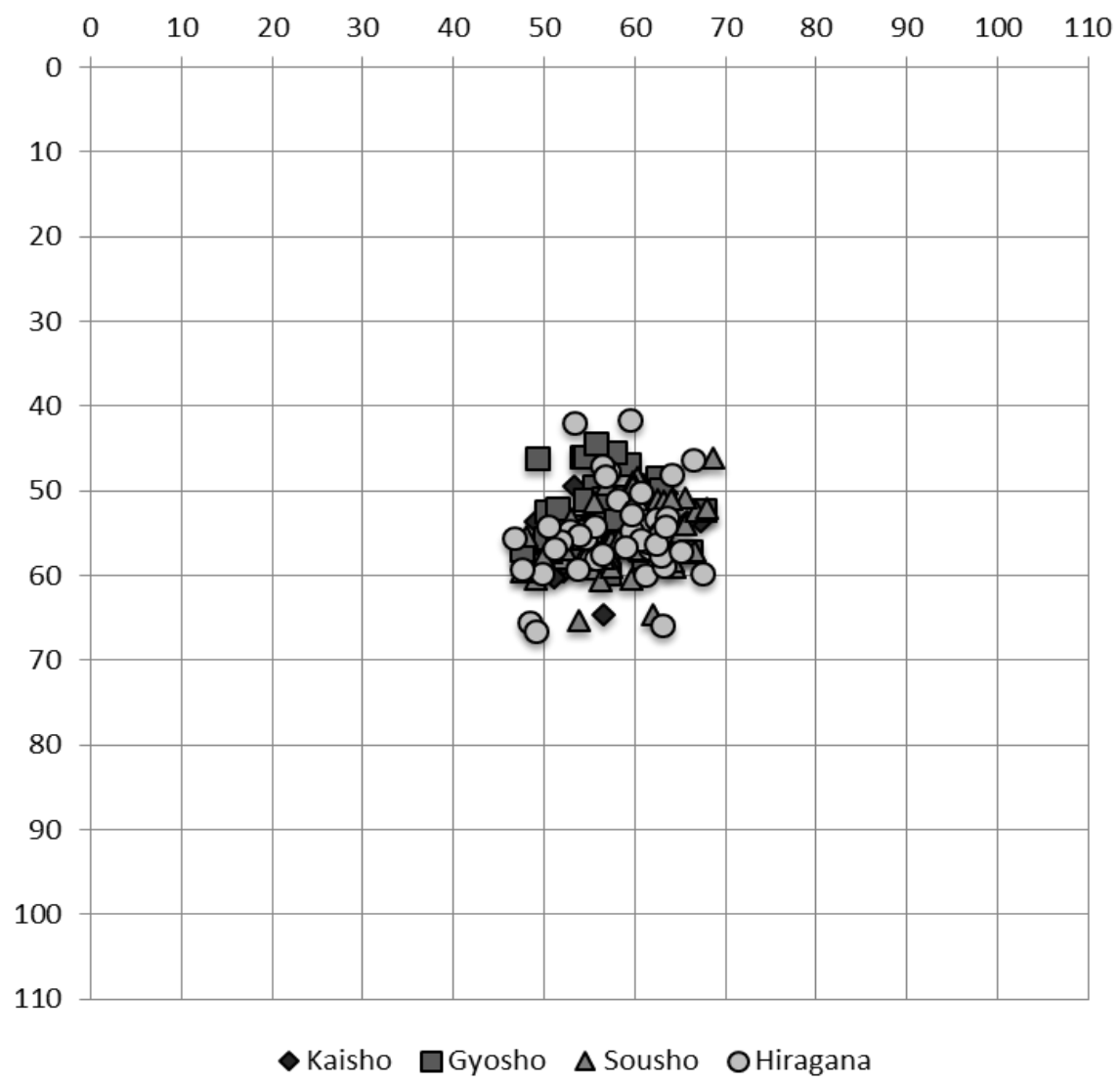

Fig. 21 Average center of gravity.

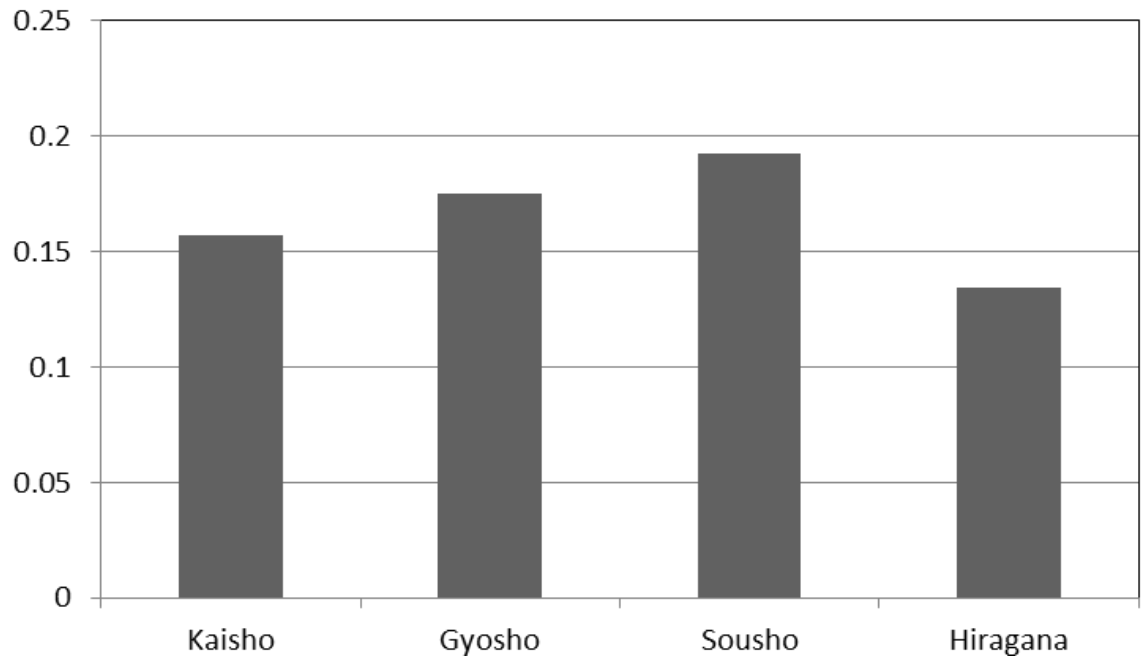

Fig. 22 Average stability index. 
relatively stable center of gravity, "Kanji" was shown higher stability than "Hiragana". The "Sousho" was most stable style than other two "Kanji", its stability index was 0.193. The stability indexes of "Kaisho" and "Gyosho" were 0.157 and 0.175 .

\section{Conclusions}

In the end, the weight coefficient ratios of vertical part-horizontal part, diagonal right part-horizontal part and diagonal left part-horizontal part were summarized in Fig. 23, which was benchmarked against "Kaisho". In the ratio of vertical part-horizontal part, the "Gyosho" and "Sousho" presented lower ratio than "Kaisho". "Hiragana" was shown similar with "Kaisho". In the ratio of diagonal rightpart-horizontal part, the "Gyosho" and "Sousho" also presented lower ratio than "Kaisho", the ratio of "Hiragana" was larger than "Kaisho" significantly. In the other ratio of diagonal leftpart-horizontal part, the ratios of three styles of "Gyosho", "Sousho" and "Hiragana" were lower than "Kaisho". The main difference of "Sumi" distribution between each chirography was reflected on vertical part and diagonal right part where were easy to connect between two adjacent strokes and characters. It should pay attention for learners, especially during calligraphy training process of "Sousho" and "Hiragana".

The indicators for each chirography were displayed in Fig. 24. Three calligraphies of "Kanji" were shown the similar indicators of stability index, "Sumi" ratio, cut-point number and smooth index. The "Hiragana" was shown smaller cut-point number comparing with "Kanji". The "Kaisho" was shown little smaller width index than other calligraphies. The results showed that a good calligraphy work has to reach an equilibrium between width of stroke, "Sumi" area and structure stable, where a learner should endeavor to do. The roundness index of "Kaisho", "Gyosho", "Sousho" and "Hiragana" appeared obvious increasing trend from low to high corresponding with calligraphy training sequence. It is considered that how to write curved strokes was the one of key points of calligraphy learning, which was the main point of identification and evaluation of the calligraphy work.

In a word, this research provided a numerical value estimate method of calligraphy work. And four kind styles of "Kaisho", "Gyosho", "Sousho" and "Hiragana" of 47 characters selected from computer and dictionary were calculated and compared as an example, which also offered a reference for learners. Learner also can use this system to evaluate their calligraphy

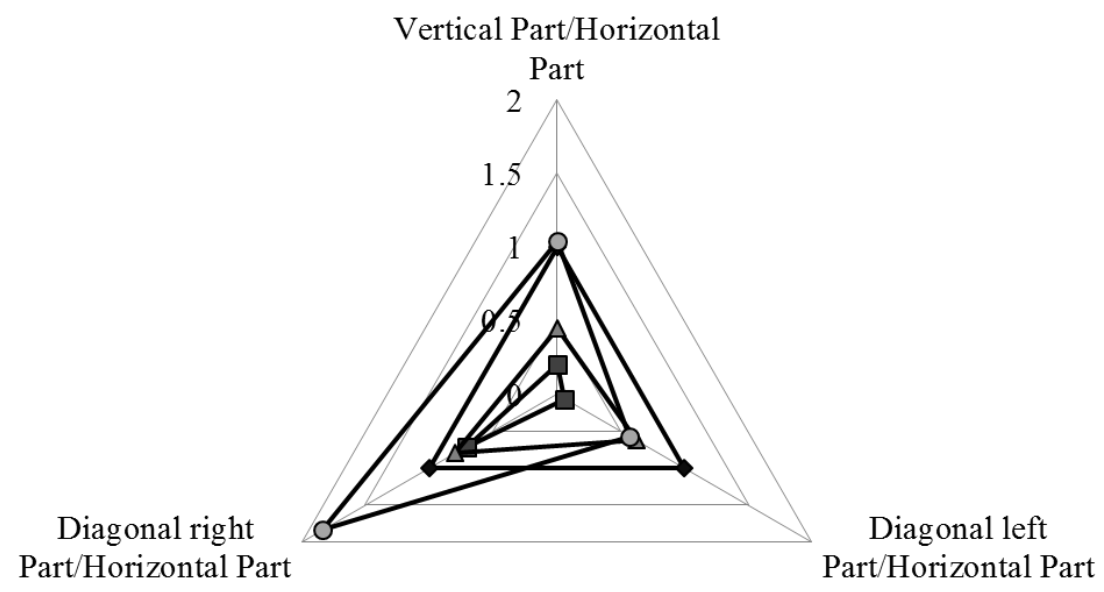

$\neg$ Kaisho $\neg$-Gyosho $\triangle-$ Sousho $-0-$ Hiragana

Fig. 23 Weight coefficient ratios of vertical par-horizontal part, diagonal right part-horizontal part and diagonal left part-horizontal part. 


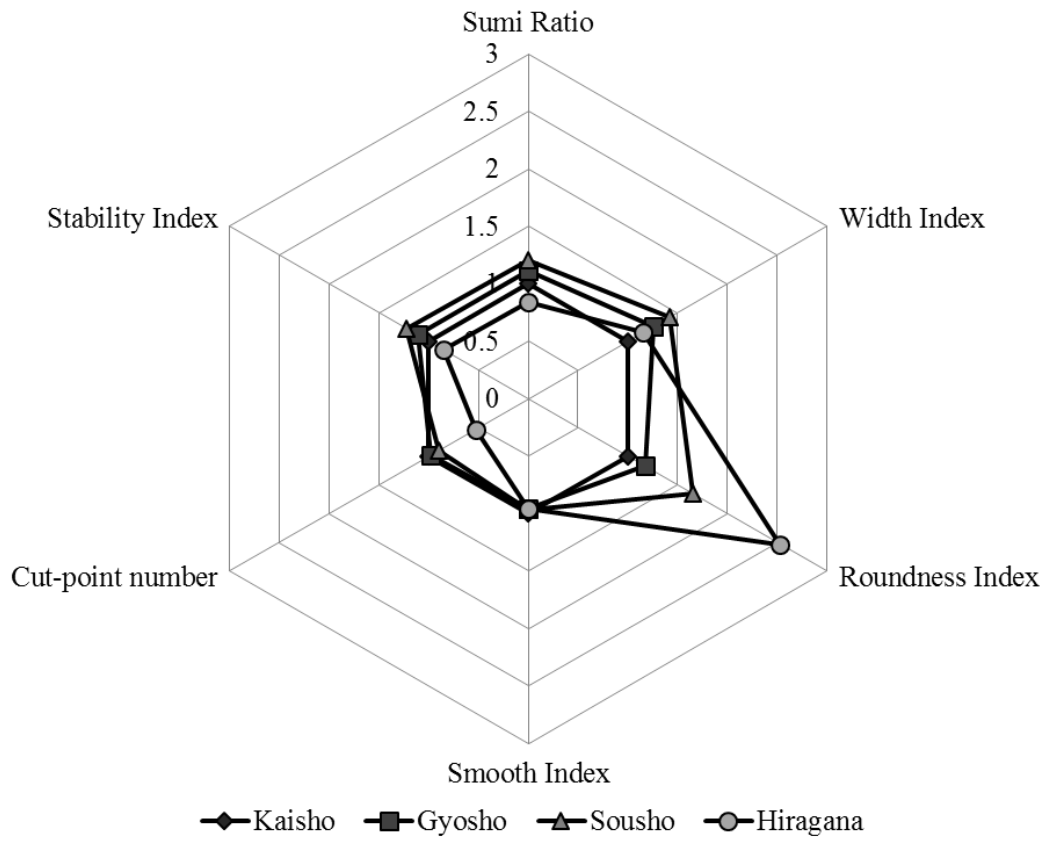

Fig. 24 Comparison diagram between four calligraphy styles.

work in order to get intuitive data and help improve their writing skill.

\section{References}

[1] Lu, W., and Max, A. 2004. "Origins and Evolution of Chinese Writing Systems and Preliminary Counting Relationships.” Accounting History 9 (3): 25-51.

[2] Qiu, X. G. 2000. Early China Special Monograph Series No. 4. Berkeley: The Society for the Study of Early China and the Institute of East Asian Studies, University of California.

[3] Available online at: https://en.wikipedia.org/wiki/Xuan_paper.

[4] Yuuko, S. 2005. An Introduction to Japanese Calligraphy. Tunbridge Wells: Search Press.

[5] Wang, Xizhi and his Calligraphy Gallery at China Online Museum:

http://www.chinaonlinemuseum.com/calligraphy-wang-xi zhi.php.

[6] Kiichirou, K. 1965. "About Three Brushes.” Calligraphy Complete Works 11. Heibonsha, new edition 1971 (first edition 1965).

[7] Zhang, X. R., Sanada, H., and Tezuka, Y. 1984. "Forming Square-Styled Brush-Written Chinese Characters with a Computer." The Transactions of the Institute of Electronics and Communication Engineers of Japan 67 (5): 599-606.

[8] Zhang, X. R., Ji, H., Sanada, H., and Tezuka, Y. 1993. "Forming Brush-Written Hiragana with the Capability of
Providing Versatile Stroke-Connecting Flows." The Transactions of the Institute of Electronics, Information and Communication Engineers J76-D-2 (9): 1868-77.

[9] Zhang, X. R., Sanada, H., and Tezuka, Y. 1986. “A Proposal of Brush-Touch Pattern Suitable for Generating Various Styles of Characters with a Computer." The Transactions of the Institute of Electronics, Information and Communication Engineers J69-D (6): 885-92.

[10] Yamada, K., and Nishimura, S., Nakamura, T., He, L. F., and Itoh, H. 2001. "Generation of Artistic Calligraphic Fonts Considering Character Structure." Forma 16: 357-66.

[11] Furusho, Y., Hirano, K., Nakamura, K., and Kotani, K. 2001. "Evaluation of Beauty for Brush Hand-Written 'Kanji' Based on Sensitivity Information." IEICE Technical Report. Image Engineering 101 (201): 81-8.

[12] Mori, M., and Sawaki, M. 2002. "A Survey of Robust Character Recognition and Its Application." Technical report of IEICE. PRMU 101 (713): 25-40.

[13] Izumi, T., Hattori, T., Kitajima, H., and Yamasaki, T. 2007. "Automated Handwritten Characters Recognition Based on a Vector Field." IEEJ Transactions on Electronics, Information and Systems 127 (4): 489-96.

[14] Park, O. S., Nonaka, T., Nishiwaki, T., Maekawa, Z., Morimoto, K., and Kurokawa, T. 2015. "Subjective and Objective Evaluation for Beauty of Hiragana." Journal of Japan Society of Kansei Engineering 5 (2): 63-9.

[15] Zenichiro, M., Shinji, Y., and Riichi, H. 2012. "Scientific Consideration on Japanese Calligraphy World." Recent Advancement of Interfacial Materials Science on 
Composite Materials 2012 (CD-ROM), Rombunno.sp17.

[16] Wang, Z. L., Liao, M., Hagihara, R., and Maekawa, Z. 2015. "Comparison between Expert and Beginner on Calligraphy Letter's Characteristic." 6th International Conference on Applied Human Factors and Ergonomics
(AHFE 2015) and the Affiliated Conferences 3: 495-502.

[17] Available online http://www.foundertype.com/EN/english.htm.

[18] Takada, C. 1998. Dictionary for Five Types of Calligraphy Letters. Houshokai. 